\title{
APUNTES DE VIAJE: RECORRIENDO LA INDIA... MANKAPUR
}

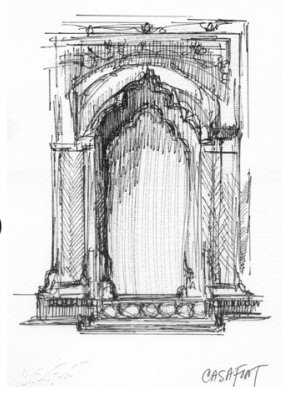

TRAVELLING NOTES: GOING OVER INDIA... MAKAPUR **

Miguel Casafont Broutin*

El enorme reloj de cansadas agujas ya casi marca las 10 de la noche, y la estación de trenes del Old Delhi se asemeja a un hormiguero recién pisoteado por algún gigante invisible: taxis, bicicletas, rickshaws y toda suerte de gentes se mueven a nuestro alrededor, en una coreografía sin aparente sentido, pero perfectamente sincronizada con el ruido de las bocinas de los automóviles atrapados en el caos vial. Desde el asiento trasero de un desvencijado taxi, mi amiga, la princesa Rajkumari Lila Singh-Kutty, se ríe ante mi gesto de preocupación por nuestra tardanza, y me juega una broma diciendo que no sabe si tiene con ella los boletos o bien los dejó perdidos en casa, haciendo un gesto de falso desconcierto.

Parece que nunca vamos a llegar a la puerta de la estación, atrapados por un tejido humano, el tiempo es lo único que no se ha detenido esta fría noche. Los altavoces aúllan en hindi números de plataformas y horas de salida, causando pánico entre quienes aún no encuentran sus lugares, como yo. A mi lado, un regimiento de kulis desfila llevando sobre sus turbantes toda clase de maletas y fardos, transfigurados en hormigas zompopas ahora presiden la marcha de casi todos los viajeros. El aire de transparente seda azul, se ha vuelto cálido por el aliento de la multitud y de repente levita sobre todas las cabezas mezclándose con el hedor del humo del diesel.

Quizá este sea el único lugar de la India donde la puntualidad militar, y como no hay tiempo para conseguir a un kuli, tomo las maletas, cargo mi mochila y a empujones trato de desfilar hacia las plataformas para buscar el tren nocturno de la línea Delhi-Lucknow.

\footnotetext{
* $\quad$ Universidad de Costa Rica.

** Traducción: Geannette Soto. Escuela de Lenguas Modernas, Universidad de Costa Rica. Correo electrónico: ucrcasafont@gmail.com Recepción: 16/04/13. Aceptación: 07/05/13.
} 
Con atinado desconcierto pregunto, ¿pero... son estos los números asignados? El boleto indica que viajamos en primera clase pero a juzgar por el tipo de vagón lo dudo. Con una inofensiva risa, la princesa me dice que sí, sí es primera clase y que nada más mire hacia atrás para prestar atención los vagones de segunda y tercera. Ante el reclamo obedezco y me acomodo en mi estrecha litera, mirando las paredes pintadas de celeste turquesa. La noche y el tren avanzan unidos... el silbato de la máquina nos despide de la ruidosa ciudad de Delhi.

Chai, chai, chai, chai,... son los graznidos del vendedor de té que anuncia el desayuno y ya ha despertado a quienes continuaban acurrucados por el vaivén del tren. Amanece y el paisaje de aldeas dormilonas, estanques de lotos azules y cielos de azafrán se asoman uno a uno por los ahumados cristales de mi ventana. Creo que después del criquet, viajar en tren es uno de los pasatiempos favoritos del pueblo indio. La vida en familia se apodera de los vagones: animadas conversaciones, rezos, partidas de naipes y el simple hecho de ver por la ventana forman parte de la tediosa rutina del viaje de casi dos días.

Lila me habla sobre su niñez y de cómo a los cinco años salió de palacio acompañada de un sirviente, rumbo al famoso internado Le Martiniere de Lucknow. Allí permaneció por 12 años, viajando sólo durante las vacaciones a su Mankapur natal, donde el glorioso pasado de su familia principesca parece sacado de un cuento de hadas. Con lágrimas en los ojos me dice que la última vez que visitó el palacio fue para el funeral de su padre. Ahora, seis meses después, esta es la primera vez que su padre no la espera en la estación.

El tren desacelera su marcha y llega a Lucknow, en el norte de India. Sin mucho pensarlo, salimos a toda prisa del vagón y caminamos varias cuadras para cambiar de estación ferroviaria y tomar un tren más pequeño rumbo a Mankapur, situado en las faldas de los Himalayas, cercano a la frontera con Nepal.

Mankapur floreció como un pequeño reino de gobernantes, pertenecientes al clan de los Kshatriya, la casta hindú de los guerreros.
Sus príncipes, emparentados con los aristócratas nepaleses, carecen hoy en día del privilegio y poderío político de antaño; viven de sus recuerdos y subsisten de los frutos de sus cosechas: el trigo, la cebada y los mangos.

Bajamos al andén, todavía agobiados por dos días de viaje y envueltos en nuestros chales de cachemira, Kachi, quien ha servido por décadas a la familia, nos recibe con una gran sonrisa, apurándose en rellenar el pequeño vehículo Ambassador con nuestro equipaje.

Cruzando por la mitad del pueblo, entre el bullicioso laberinto del bazar, el chofer toma un polvoriento desvío para llegar hasta lo que será nuestro hogar por casi un mes. Bautizada con el nombre sánscrito de Aparajita, el invicto, esta enorme construcción solariega de dos pisos se muestra majestuosa en medio de una formidable plantación de mangos.

Lila me conduce a mi habitación en el segundo piso, sobria, pero de grandes dimensiones y decorada de manera austera apenas salpicada con exquisitas miniaturas rajput en sus paredes. Junto al enorme balcón con vista a los Himalayas, me presenta a su madre, una simpática señora que está feliz de tenerme como invitado. En India a un huésped siempre se le trata como a una deidad, pues se supone que llena de bendiciones al hogar que visita. Con las palmas de las manos juntas, hago un saludo de Namaskar y comprendo como en la India la hospitalidad es una expresión del culto a lo divino.

Mankapur tiene en su geografía a varios palacios, muchos decorados con los emblemas de peces que usaban los Nawabs de Lucknow. La inventiva local, quizá inspirada por el estilo neoclásico del siglo XVIII, se encargó de construir estos enormes edificios, con una mezcla de la estética india y la europea, pero que hoy urgen de ser restaurados. En todos hay enormes campanas que proclaman al viento, como un reloj, las horas del día, la música de la siembra, la cosecha, el almuerzo y el fin de la faena de la tarde.

La mañana comienza cuando el sirviente me despierta con una fragante taza de té rociado de cardamomo, nuez moscada, clavo de olor y 
canela. Después tomo el desayuno y antes del baño, con agua mineral de pozo, la costumbre es recibir un extenso masaje con aceite de mostaza caliente. Luego del almuerzo le sigue una leve siesta y a las tres de la tarde sube Kachi para ayudarme a vestir el dhoti, nueve metros de tela de fino algodón que hay que drapear al cuerpo; éste sin duda es el más antiguo y formal de los trajes de la India. Dentro de una hora, el tío de Lila, el príncipe de mayor edad de Mankapur y su pequeña corte, nos esperan en otro palacio para tomar el té.

Para la audiencia familiar, Lila y su madre van ataviadas con saris de gala y resplandeciendo con antiguas joyas de familia. En el diminuto auto viajan con nosotros, Kachi y Mona, la otra sirvienta, en un recorrido de escasos diez minutos pero que exige de la pompa de un Durbar, aunque se trate solamente de ir a ver a sus tíos y primos.

Arribamos al palacio color marfil y los sirvientes nos conducen, pasando por un jardín de rosas, hasta el segundo piso, traspasando por enormes estancias de altos techos de doble altura. La realeza en el exilio nos recibe en un salón con vista a la gran terraza, rodeados de maravillosas alfombras, cojines bordados, pieles disecadas de tigres de bengala y hermosas fotografías antiguas.

Días después mi visita se enriquece al conocer la vida de los aldeanos. Antes del alba me despierto para ir caminando hasta la aldea con un singular fin: aprender a ordeñar búfalas. La leche de estos bovinos es muy apreciada en la India, rica en grasa y nutrientes ya que se puede mantener sin refrigeración por varios días.

La sorpresa de las gentes es única, pues ataviado con un lunghi me dispongo como otro lugareño más a ordeñar la leche de la mañana. Las risas y el lenguaje de señas son el idioma universal para hacerse entender y éstos se suman a una ronda de aplausos que celebran un balde que pude medio llenar con preciado líquido.

Mis mañanas transcurren dedicadas a la pintura y al dibujo, otras veces las paso hurgando entre los viejos libros de arte e historia de la India en la vasta biblioteca del palacio. Los días se entremezclan con largas excursiones y visitas a varios sitios sagrados como Ayodhya, una de las siete ciudades santas del hinduismo donde se dice que nació Rama. Algunas tardes las paso entre las tertulias que se arropan en los palacios, para terminar el día observando el paisaje nocturno rasguñado por lejanas tormentas eléctricas y cielos escarchados de infinitas estrellas.

Al despedirnos, la madre de Lila me obsequia un hermoso sari de seda con pesados hilos de oro que calcula tiene más de cien años, un textil exquisito herencia de familia que ahora debo llevar a mi mamá. Con una pícara frase y bromeando, mi amiga la princesa agrega, "si su mamá no lo usa, puede colocarlo en una olla, bañarlo en alcohol, prenderle fuego y al final cuando se evapora la seda, tendrá suficiente oro para un anillo"

Empacados los recuerdos, las pinturas, dibujos y bocetos; con las maletas cargadas de obsequios como dulces caseros y chutney, partimos de nuevo a la estación, esta vez bajo un cielo de pálidos tonos de cúrcuma, donde aguarda el tren de regreso a Delhi. Digo adiós, o mejor aún, un hasta pronto y Namaskar, a un mundo mágico que, como todo en la India, a veces me parece que fue inventado por mi imaginación de artista.

\section{Glosario}

Cachemira: Textil típico de esta región homónima cercana a los Himalayas, mezcla de lana y pelo de cabra.

Chai: Bebida típica de la India, elaborada con té negro, leche, miel y una mezcla de especias que varían según la región y que pueden incluir cardamomo, canela, nuez moscada, jengibre.

Chutney: Encurtido picante o confitura elaborada con frutas y verduras cocinadas en vinagre con azúcar a la cual se le añaden condimentos típicos de la India. Se usan como acompañamientos de las comidas y entre los más populares están los de mango, tomate, coco y culantro.

Durbar: Reunión ceremonial de gran pompa y boato, término muy usado durante el dominio británico en la India. 
Dhoti: Tela larga de algodón (7 ó 9 m.) que a manera de pantalón va atado, sin costuras, a la cintura del hombre.

Kuli: En la actualidad,nombre con el que se designa a los maleteros de las estaciones de tren en la India. Usualmente, se les identifica por estar vestidos de rojo.

Lunghi: Falda de colores que solo usan los hombres.

Namaskar: Saludo formal de la India. Con las palmas de las manos juntas significa yo saludo al espíritu divino que habita en usted.

Nawabs: Gobernadores de la clase aristócrata.

Rajkumari: Princesa, la hija del rey (de Raja: rey).
Rajput: Estilo de pintura miniatura con escenas propias de las cortes mogules del siglo XVII.

Rama: En el hinduismo, él es un avatar ('descenso' de Dios) de Visnú, nacido en Ayodhya, al norte de la India.

Rickshaw: Volanta tirada por un hombre.

Sari: Vestido tradicional de la mujer india, compuesto por una sola pieza de tela de 7 metros que se enrolla a manera de drapeado y sin costuras al cuerpo.

Zompopa: Hormigas cortadoras de hojas, de color rojo (Atta cephalotes). 